\title{
Implementation of a Fast-Track Perioperative Care Program: What Are the Difficulties?
}

\author{
Sebastiaan W. Polle ${ }^{a}$ Jan Wind ${ }^{a}$ Jan W. Fuhring ${ }^{a} \quad J^{a n}$ Hofland $^{b}$ \\ Dirk J. Gouma ${ }^{a}$ Willem A. Bemelman ${ }^{a}$ \\ Departments of a Surgery and ${ }^{\mathrm{b}}$ Anesthesiology, Academic Medical Center, University of Amsterdam, \\ Amsterdam, The Netherlands
}

\section{Key Words}

Colorectal cancer $\cdot$ Colorectal surgery $\cdot$ Crohn's disease $\cdot$ Laparoscopy $\cdot$ Ulcerative colitis

\begin{abstract}
Background: To evaluate the feasibility of a fast-track (FT) program and it's effect on postoperative recovery. Methods: All patients, scheduled for elective segmental colorectal resection were treated in a FT program (FT group). Data were compared to a control group operated for elective colorectal resections and treated in a traditional care program (TC group). Data from the FT group were collected prospectively, data from the TC group retrospectively. Outcome parameters included the number of successfully applied FT modalities, patient satisfaction, morbidity rate, re-operation rate, primary (PHS) and total hospital stay (THS), and readmission rate. Results: One-hundred and seven patients were included (55 FT group vs. 52 TC group). The groups were comparable for patient characteristics such as age and $\mathrm{cr}$ POSSUM score $(p=0.22$ and $p=0.40)$. An average of 7.4 of 13 predefined FT modalities were successfully achieved per patient. Patient satisfaction was comparable $(p=0.84)$. Seven versus 5 patients required a re-operation in the FT and TC groups, respectively $(p=0.52)$. Morbidity rate was comparable ( $n=16$ vs. $15, p=0.83$ ). Median PHS was 4.0 vs. 6.0 days and median THS was 4.0 vs. 6.5 days in the FT and TC groups
\end{abstract}

( $p<0.01$ and $p<0.03$, respectively). Six vs. 3 patients were re-admitted in the FT and TC groups, respectively $(p=0.49)$. Conclusion: Implementation of all FT modalities was difficult since a rather low number of pre-defined FT modalities was effectively realized. Despite incomplete implementation, PHS and THS were shorter in the FT group without affecting patient satisfaction.

Copyright $\odot 2007$ S. Karger AG, Basel

\section{Introduction}

Fast-track (FT) programs, also referred to as enhanced recovery after surgery (ERAS), are supposed to reduce morbidity, accelerate recovery and consequently shorten hospital stay of surgical patients [1, 2]. Kehlet et al. [3] achieved a reduction in hospital stay from 10 to 3.3 days for patients undergoing segmental colonic resection. To a lesser degree, others have also reported a reduction in hospital stay after the implementation of a FT program [4-8]. Although the number of studies reporting the advantages of FT care programs is growing, the evidence is still rather limited; only 3 small randomized controlled trials (RCTs), encompassing a total number of 64 patients treated in a FT perioperative care program, have been published [9]. Most of the available nonrandomized studies have a retrospective design or are case series without

\section{KARGER}

Fax +4161306 1234 E-Mail karger@karger.ch www.karger.com
(ㄷ) 2007 S. Karger AG, Basel

0253-4886/07/0246-0441\$23.50/0

Accessible online at:

www.karger.com/dsu
Prof. Dr. W.A. Bemelman

Department of Surgery, Academic Medical Center, University of Amsterdam PO Box 22660

NL-1100 DD Amsterdam (The Netherlands)

Tel. +31 20566 6818, Fax +31 20691 4858,E-Mail w.a.bemelman@amc.uva.nl 
Table 1. Evaluated fast-track modalities

Omission of bowel preparation

Prevention of hypothermia

Preoperative counseling by FT nurse

Intake of $4 \mathrm{CHL}$ drinks on day before surgery

Epidural anesthesia

Prophylactic PONV medication

Intake of $2 \mathrm{CHL}$ drinks $2 \mathrm{~h}$ before surgery

Suprapubic catheter

Omission of evening medication

Omission of premedication

Intake of $2 \mathrm{CHL}$ drinks on evening after surgery

Early extension of oral liquids

Early mobilization

$\mathrm{CHL}=$ Carbohydrate-loaded drink $\left(\right.$ Nutridrink $\left.^{\circledR}\right) ;$ PONV $=$ postoperative nausea or vomiting.

adequate control groups and without reporting on patient satisfaction with such a program [10-13]. Although the combination of laparoscopic surgery and FT care might be the optimal strategy, only two RCTs have compared laparoscopic to open surgery within a FT program $[14,15]$. The conflicting results of these reports justify further study.

While most authors have meticulously described the FT modalities included in their protocols (e.g. omission of bowel preparation and premedication, use of thoracic epidural anesthesia for perioperative analgesia management, early postoperative mobilization and feeding), none of them actually described the degree of compliance with each of the single FT modalities as defined in their protocols. For this reason, the exact influence of the number of and type of FT modalities within a FT program remains unknown. Moreover, most authors publishing their results after introduction of a FT program probably make their report after an initial period of pilot testing with such a program. No data are available with respect to the encountered early difficulties with the introduction of such a program.

The objective of this study was therefore to describe our results from the start of introduction of a FT program by evaluating both the number of successfully applied predefined FT modalities per patient as well as the combined effect of these FT modalities on postoperative recovery. These results were compared to results of patients treated in a traditional care (TC) program. The faced bottlenecks with the introduction of the program will be commented on.

\section{Materials and Methods}

In the Academic Medical Center in Amsterdam two separate gastrointestinal surgery units are available. A FT perioperative care program was introduced in one of the two gastrointestinal surgery units in August 2004 (FT unit). Patients scheduled for elective abdominal segmental colorectal resection including ileocolic (re-)resection in the period August 2004 to July 2005, and admitted on the FT unit, were treated according to the FT program (FT group). The allocation of patients to the unit with FT or the unit without FT in this period, depended on the availability of hospital beds on both units, the availability of a FT nurse, and the FT surgeon who initiated this project. A consecutive series of patients, scheduled for elective segmental colorectal resection in the period June 2003 to January 2004 and admitted to both gastrointestinal surgery units, was treated in a traditional care program and served as a control group (TC group). Only patients with American Society of Anesthesiologists (ASA) classification I or II were included in this study. In both study groups, patients with prior segmental colorectal resections were included as were both open and laparoscopic procedures. Patients requiring a palliative resection or an abdominoperineal resection (APR) for colorectal cancer were excluded. Outcome data of the FT group were recorded prospectively; outcome data of the TC group were collected retrospectively from patients' records. All data were analyzed according to an intention-to-treat principle meaning that patients who were unable to fulfill (parts of) the FT program were analyzed in the FT group. Since each single modality as applied in our FT program is an accepted form of treatment in daily care, no ethics approval from our ethics committee was requested. Each patient was, however, informed about the combination of these accepted and evidence-based single modalities applied in the FT protocol.

Primary outcome parameters were the number of successfully applied FT modalities per patient and patient satisfaction. Secondary outcome parameters were overall morbidity rate, reoperation rate, primary hospital stay, total hospital stay, readmission rate, and mortality rate.

A total of 13 FT modalities were identified (table 1). For each patient each modality was evaluated for successful implementation (e.g. if bowel preparation was omitted it was scored as successful implementation, if it was not omitted it was considered unsuccessful). In this manner, all successfully applied items per patient were scored. Also, the average number of successfully applied items of all patients was calculated. Overall morbidity was defined as any complication requiring an unplanned intervention within 30 days after the operation. A major complication was considered any complication requiring a surgical reintervention or resulting in permanent adverse sequelae (such as myocardial infarction). Total hospital stay was defined as primary hospital stay plus the hospitalization period of patients that were readmitted within 30 days after surgery.

\section{Fast-Track vs. Traditional Care Protocol}

Details of the FT perioperative and traditional care protocols are summarized in table 2. Discharge criteria were similar for both groups consisting of (1) adequate pain control with oral medication; (2) absence of nausea; (3) passage of first flatus and/or stool; (4) ability to tolerate solid food; (5) mobilization and self-support as preoperative, and (6) acceptance of discharge by the patient. 
Table 2. Differences between fast-track and traditional care protocol

\begin{tabular}{|c|c|c|}
\hline & Fast-track care & Traditional care \\
\hline \multicolumn{3}{|l|}{ Preoperative phase } \\
\hline $\begin{array}{l}\text { Outpatient department } \\
\text { of surgery }\end{array}$ & $\begin{array}{l}\text { - Scheduling of operation } \\
\text { - Information about FT } \\
\text { - Informed consent }\end{array}$ & - Scheduling of operation \\
\hline $\begin{array}{l}\text { Outpatient department } \\
\text { of anesthesiology }\end{array}$ & $\begin{array}{l}\text { - Pre-assessment for risk adjustment } \\
\text { - Discussion focusing on placement of thoracic } \\
\text { epidural catheter for management of perioperative } \\
\text { analgesia }\end{array}$ & $\begin{array}{l}\text { - Pre-assessment for risk adjustment } \\
\text { - Open discussion about different possibilities for management } \\
\text { of perioperative analgesia (i.e. placement of epidural catheter } \\
\text { on any level, patient controlled analgesia with morphine } \\
\text { (PCA-morphine) or continuous i.v. morphine infusion) }\end{array}$ \\
\hline $\begin{array}{l}\text { Pre-admission guided } \\
\text { tour on surgical ward }\end{array}$ & - Yes & - No tour \\
\hline \multicolumn{3}{|l|}{ Day of admission } \\
\hline Preoperative fasting & $\begin{array}{l}\text { - Last meal } 6 \mathrm{~h} \text { before operation } \\
\text { - Last clear drink (CHL) } 2 \mathrm{~h} \text { before operation }\end{array}$ & $\begin{array}{l}\text { - Last meal until midnight } \\
\text { - No oral intake at the day of surgery }\end{array}$ \\
\hline Preanesthetic medication & $\begin{array}{l}\text { - Lorazepam, } 1 \mathrm{mg} \text { the evening before operation if } \\
\text { necessary } \\
\text { - No sedative medication at the day of operation }\end{array}$ & $\begin{array}{l}\text { - Lorazepam, } 1 \mathrm{mg} \text { or temazepam } 10 \text { or } 20 \mathrm{mg} \text { the evening } \\
\text { before operation } \\
\text { - Lorazepam } 1 \mathrm{mg} \text {, temazepam } 10 \text { or } 20 \mathrm{mg} \text {, or midazolam } \\
7.5 \mathrm{mg} \text { at the day of operation }\end{array}$ \\
\hline \multicolumn{3}{|l|}{ Day of surgery } \\
\hline Anesthetic management & $\begin{array}{l}\text { - Placement of thoracic epidural catheter }(\mathrm{T} 6-\mathrm{T} 10 \text {, } \\
\text { depending on the surgical resection); test-dose } \\
\text { (bupivacaine } 0.25 \% \text { with adrenaline } 1: 200,000 \text { ), } \\
\text { top-up dose (bupivacaine } 0.25 \%[ \pm 10 \mathrm{ml}] \text { with } \\
\text { sufentanil } 25 \mu \mathrm{g} \text {, followed by continuous infusion } \\
\text { (bupivacaine } 0.125 \% \text { with fentanyl } 2.5 \mu \mathrm{g} \cdot \mathrm{ml}^{-1} \text { ) } \\
\text { until day } 2 \text { postoperatively } \\
\text { - } \text { Combined with balanced general anesthesia } \\
\text { - Restricted per-operative fluid infusion regime } \\
\text { (Ringers lactate } 20 \mathrm{ml} \cdot \mathrm{kg}^{-1} \text { in the } 1 \mathrm{st} \text { h followed } \\
\text { by RL } 6 \mathrm{ml} \cdot \mathrm{kg}^{-1} \cdot \mathrm{h}^{-1} \text { ) } \\
\text { - Use of vasopressor drugs as } 1 \mathrm{st} \text { choice for } \\
\text { management of mean blood pressure drop }>20 \% \\
\text { of baseline } \\
\text { - Forced body heating (Bair hugger system and } \\
\text { warmed i.v. fluids) } \\
\text { - Removal of nasogastric tube before extubation } \\
\text { - Prophylactic use of odansetron (4 mg) to prevent } \\
\text { PONV }\end{array}$ & $\begin{array}{l}\text { - i.v. morphine loading }\left(0.1 \mathrm{mg} \cdot \mathrm{kg}^{-1}\right) \text { followed by continuous } \\
\text { i.v. morphine infusion or PCA-morphine, OR placement } \\
\text { of epidural catheter (T10-L1, test dose, top-up dose and } \\
\text { continuous infusion in the same way as for fast-track) when } \\
\text { an open surgical procedure will be performed } \\
\text { - i.v. morphine loading }\left(0.05-0.1 \mathrm{mg} \cdot \mathrm{kg}^{-1}\right) \text { followed by } \\
\text { PCA-morphine or continuous i.v. morphine infusion } \\
\text { when a laparoscopic surgical procedure is performed } \\
\text { - Combined with balanced general anesthesia } \\
\text { - Standard per-operative fluid infusion regime (Ringers lactate } \\
\left.20 \mathrm{ml} \cdot \mathrm{kg}^{-1} \text { in the } 1 \mathrm{st} \mathrm{h} \text { followed by } \mathrm{RL} 10-12 \mathrm{ml} \cdot \mathrm{kg}^{-1} \cdot \mathrm{h}^{-1}\right) \\
\text { - Use of extra fluid challenge as } 1 \mathrm{st} \text { choice for management of } \\
\text { mean blood pressure drop }>20 \% \text { below baseline } \\
\text { - Forced body heating (Bair hugger system and warmed i.v. } \\
\text { fluids) } \\
\text { - Nasogastric tube remain until day } 1 \text { after surgery } \\
\text { - Use of odansetron, dexamethason or droperidol for PONV } \\
\text { management according to attending anesthesiologist }\end{array}$ \\
\hline Surgical management & $\begin{array}{l}\text { - Minimal invasive incisions } \\
\text { - Suprapubic urine catheter } \\
\text { - Infiltration of surgical wounds with bupivacaine } \\
\text { - No standard use of abdominal drains }\end{array}$ & $\begin{array}{l}\text { - Median laparotomy approach } \\
\text { Urine catheter according to attending surgeon } \\
\text { - No infiltration of surgical wounds with local anesthetic drugs } \\
\text { - Standard use of abdominal drains }\end{array}$ \\
\hline $\begin{array}{l}\text { Early postoperative } \\
\text { management }\end{array}$ & $\begin{array}{l}\text { - Use of epidural catheter as mentioned before to } \\
\text { which paracetamol } 4 \times 1 \mathrm{~g} \cdot \mathrm{d}^{-1} \text { is added } \\
\text { - First oral drinks at } 2 \mathrm{~h} \text { postsurgery }+ \text { i.v. infusion } \\
\text { of RL } 1.5 \text { liters } \cdot \text { day }{ }^{-1} \\
\text { - Mobilization in the evening }(>2 \mathrm{~h} \text { out of bed) } \\
\text { - First semi-solid food intake in the evening }\end{array}$ & $\begin{array}{l}\text { - Continuous i.v. morphine infusion or PCA-morphine OR use } \\
\text { of epidural catheter as mentioned before to which paracetamol } \\
4 \times 1 \mathrm{~g} \cdot \text { day }^{-1} \text { and } / \text { or diclofenac } 3 \times 50 \mathrm{mg} \cdot \text { day }^{-1} \text { are added } \\
\text { - Small amount of water orally }+ \text { i.v. infusion of } \\
\text { RL } 2.5 \text { liters } \cdot \text { day }^{-1} \\
\text { - } \text { Bedrest }\end{array}$ \\
\hline Day 1 after surgery & $\begin{array}{l}\text { - Oral intake }>21 \text { (including } 4 \text { units CHL drinks), } \\
\text { offer solid food } \\
\text { - Stop i.v. fluid administration (leave cannula) } \\
\text { - Start laxative }\left(\mathrm{MgO}, 2 \times 1 \mathrm{~g} \cdot \mathrm{day}^{-1}\right) \\
\text { - } \text { Close suprapubic urine catheter and remove when } \\
\text { residue }<50 \mathrm{ml} \\
\text { - } \\
\text { Expand mobilization }(>6 \mathrm{~h} \text { out of bed })\end{array}$ & $\begin{array}{l}\text { - Diet increased on daily basis when normal bowel sounds are } \\
\text { examined } \\
\text { - } \text { i.v. fluid administration }\left(2.5 \text { liters } \cdot \text { day }^{-1}\right) \text { is continued till } \\
\text { adequate oral fluid intake } \\
\text { - Start laxative }\left(\mathrm{MgO}, 2 \times 1 \mathrm{~g} \cdot \mathrm{day}^{-1}\right) \\
\text { - } \quad \text { Close suprapubic urine catheter and remove when residue } \\
\quad<50 \mathrm{ml}\end{array}$ \\
\hline
\end{tabular}


Table 2 (continued)

\begin{tabular}{|c|c|c|}
\hline & Fast-track care & Traditional care \\
\hline Day 2 after surgery & $\begin{array}{l}\text { - Offer solid food } \\
\text { - Expand mobilization }(>8 \mathrm{~h}) \\
\text { - Plan discharge }\end{array}$ & - Continue as on day 1 until discharge criteria are fulfilled \\
\hline Day 3 after surgery & $\begin{array}{l}\text { - Remove epidural catheter } \\
\text { - Continue paracetamol } 4 \times 1,000 \mathrm{mg} \\
\text { - Add NSAID } \\
\text { - Remove i.v. cannula } \\
\text { - Expand mobilization }(>8 \mathrm{~h}) \\
\text { - Evaluating discharge criteria; discharge if fulfilled }\end{array}$ & - Continue as on day 1 until discharge criteria are fulfilled \\
\hline Day 4 after surgery & $\begin{array}{l}\text { - Continue as on day } 3 \text { until discharge criteria are } \\
\text { fulfilled }\end{array}$ & - Continue as on day 1 until discharge criteria are fulfilled \\
\hline
\end{tabular}

Within 24-48 h after discharge, FT patients were contacted by telephone by a specially trained FT senior nurse (J.W.F.) to check for complications. During this contact, patients were encouraged to ask questions about their recovery and reassured when necessary. All patients (both TC and FT) were seen at the outpatient department at a minimum of 30 days postoperatively. Complications in the period after discharge, if any, were recorded.

\section{Analysis of Outcome Parameters}

To evaluate a possible learning effect with the implementation of the FT protocol, a comparison was made between the first and second half of patients treated since the introduction of the FT care program (period 1: 08-2004 to 12-2004 and period 2: 01-2005 to $07-2005)$.

To assess patient satisfaction with the hospitalization, a selfreport questionnaire consisting of 16 modalities, was sent to all FT patients within 30 days after discharge. This questionnaire is used routinely in our hospital and includes questions concerning intake on the surgical ward, degree of personal attention from the surgeon and nurse, transfer of information of medical results, arrangement of discharge and questions concerning aftercare. $\mathrm{Pa}$ tients were asked to rate their satisfaction with each single modality on a Likert scale ranging from 1 (dissatisfied) to 5 (very satisfied). The scores of each question are combined to form a total patient satisfaction score ranging from 16 (lowest patient satisfaction) to 80 (highest patient satisfaction). The same questionnaire was used previously to monitor patient satisfaction in the year 2003. Patient satisfaction of FT patients was compared to that of patients from the TC group.

Also a comparison was made between patients who underwent open resection with those who underwent a laparoscopic resection, according to the type of perioperative care. So, a subanalysis of 4 subgroups was performed: (1) open resection and FT care (open FT group); (2) laparoscopic resection and FT care (Lap FT group); (3) open resection and traditional care (open TC group), and (4) laparoscopic resection and traditional care (Lap TC group).
Statistical Analysis

Data are presented as median values with ranges for continuous and discrete data, unless otherwise specified. Categorical data are presented as frequencies or percentages. Differences between groups were tested using Kruskal Wallis test or MannWhitney $U$ test for continuous data, depending on the number of groups compared. The Fisher's exact test or $\chi^{2}$ test when appropriate were used to test for differences between groups in case of categorical data. $p<0.05$ was considered statistically significant for all tests. Statistical analysis was done using the SPSS v. 12.0 package (SPSS, Chicago, Ill., USA).

\section{Results}

A total of 107 patients were included in this study: 55 in the FT group and 52 in the TC group. None of the patients eligible for the FT program refused participation in the study. Patient characteristics of the FT and TC patients are shown in table 3. The FT and TC groups were comparable for all patient characteristics although there were more open procedures and a trend to more stomas in the TC compared to the FT group. Within the FT group, patient characteristics of patients treated in the first and second FT period were comparable (data not shown). Patient characteristics of the four subgroups (data not shown) were comparable except for a higher number of primary diverting stomas in the open TC group compared to the laparoscopic FT group $(\mathrm{p}<0.01)$.

\section{Protocol Compliance}

An average of 7.4 of a potential of 13 evaluated FT modalities were successfully applied per patient. Results of 
Table 3. Patient characteristics and type of resection according to care protocol

\begin{tabular}{|c|c|c|c|}
\hline & $\mathrm{TC}(\mathrm{n}=52)$ & $\mathrm{FT}(\mathrm{n}=55)$ & $\mathrm{p}^{\mathrm{a}}$ \\
\hline Median age, years (range) & $47(18-89)$ & $49(20-79)$ & $0.224^{\mathrm{b}}$ \\
\hline ASA, \% & & & 0.402 \\
\hline 1 & 25.0 & 32.7 & \\
\hline 2 & 75.0 & 67.3 & \\
\hline Gender ratio $(M: F), n$ & $21: 31$ & $13: 42$ & 0.096 \\
\hline Body mass index, median (range) & $24.0(15.2-37.7)$ & $23.5(15.7-39.3)$ & $0.803^{\mathrm{b}}$ \\
\hline CR-POSSUM operative severity score, median (range) & $7.0(7-11)$ & $7.0(7-13)$ & $0.395^{\mathrm{b}}$ \\
\hline Type of operation & & & $0.804^{\mathrm{c}}$ \\
\hline Ileocolic (re-)resection, n (\%) & $15(28.8)$ & $19(34.5)$ & \\
\hline Right hemicolectomy, n (\%) & $10(19.2)$ & $6(10.9)$ & \\
\hline Sigmoid resection, $\mathrm{n}(\%)$ & $12(23.1)$ & $17(30.9)$ & \\
\hline Rectal resection (anterior + low anterior), $\mathrm{n}(\%)$ & $10(19.2)$ & $10(18.2)$ & \\
\hline Subtotal/total resection, $\mathrm{n}(\%)$ & $3(5.8)$ & $2(3.6)$ & \\
\hline Other partial colonic resection, $\mathrm{n}(\%)$ & $2(3.8)$ & $1(1.8)$ & \\
\hline Indication for resection & & & 0.695 \\
\hline Malignant disease, $\mathrm{n}(\%)$ & $21(40.4)$ & $20(36.4)$ & \\
\hline Benign disease, $\mathrm{n}(\%)$ & $31(59.6)$ & $35(63.6)$ & \\
\hline Laparoscopic operation, n (\%) & $17(32.7)$ & $29(52.7)$ & 0.051 \\
\hline Primary (temporary) stoma, $\mathrm{n}(\%)$ & $13(25.0)$ & $7(12.7)$ & 0.138 \\
\hline
\end{tabular}

FT = Fast-track group; TC $=$ traditional care group. CR-POSSUM = colorectal physiological and operative severity score for the enumeration of mortality and morbidity.

${ }^{a}$ Fisher's exact test unless otherwise specified; ${ }^{b}$ Mann-Whitney $U$ test; ${ }^{c} \chi^{2}$ test.

the degree of protocol compliance per FT modality are given in table 4, ranging from $13 \%$ (intake of $2 \mathrm{CHL}$ drinks the evening after surgery) to $100 \%$ (prevention of hypothermia and omission of bowel preparation).

There were no differences in protocol compliance between the first and the second FT period in any of the evaluated variables, although a small improvement in the number of patients receiving epidural analgesia in the second FT period could be observed (FT period 1 vs. FT period 2: 58 vs. $81 \%$, respectively; $\mathrm{p}=0.08$ ).

\section{Patient's Satisfaction}

The response rate of the patient's satisfaction questionnaire was $78 \%$ and $81 \%$ in the FT and TC groups, respectively. Total patients' satisfaction score was comparable in both groups (50.4 and 49.8 of a potential 80 points in the FT and TC groups, respectively; $\mathrm{p}=0.84$ ). The intake at the surgical ward was evaluated more positively in the FT group (mean score 3.8 and 3.3 in the FT and TC groups, respectively; $\mathrm{p}=0.02$ ). Satisfaction between the two groups with all of the other single modalities was comparable.

Fast-Track Perioperative Care Program
Outcome after FT vs. Traditional Care (table 5)

Overall morbidity and number of major and minor complications of the FT and TC groups were comparable. However, it seemed that more patients in the FT group had an anastomotic leakage ( $\mathrm{n}=6(11 \%)$ vs. $\mathrm{n}=2(4 \%)$, $p=0.27)$. Re-operation rate was comparable and median primary hospital stay was reduced by 2 days $(\mathrm{p}<0.01)$. Despite an increase in the number of re-admissions in the FT group, total hospital stay was reduced by 2.5 days $(\mathrm{p}=0.03)$. There was no mortality within 30 days after surgery in either group.

\section{Outcome after First FT Period Compared to}

Second FT Period (FT Patients Only)

Overall morbidity rate seemed to decrease in the second compared to the first FT period (period I: $\mathrm{n}=10 \mathrm{vs}$. period II: $n=5, p=0.07$ ) as was the case for the number of major complications (period I: $\mathrm{n}=6$ vs. period II: $\mathrm{n}=$ $2, \mathrm{p}=0.07$ ). Primary hospital stay was 4 days in both periods and total hospital stay was 4.5 days in the first FT period compared to 4.0 days in the second FT period $(\mathrm{p}=0.43)$. All other evaluated outcome parameters for both periods were comparable as well (data not shown).

Dig Surg 2007;24:441-449 445 
Table 4. Degree of protocol compliance in FT patients per evaluated modality

\begin{tabular}{|c|c|}
\hline Evaluated modality & Degree of compliance \\
\hline \multicolumn{2}{|l|}{ Omission of bowel preparation } \\
\hline Yes, n (\%) & $55(100)$ \\
\hline No, $\mathrm{n}(\%)$ & $0(0)$ \\
\hline \multicolumn{2}{|l|}{ Prevention of hypothermia } \\
\hline Yes, $\mathrm{n}(\%)$ & $55(100)$ \\
\hline No, n (\%) & $0(0)$ \\
\hline \multicolumn{2}{|l|}{ Preoperative counselling by FT nurse } \\
\hline Yes, n (\%) & $48(87.3)$ \\
\hline No, $n(\%)$ & $7(12.7)$ \\
\hline \multicolumn{2}{|c|}{ Intake of $4 \mathrm{CHL}$ drinks on day before surgery } \\
\hline Yes, $\mathrm{n}(\%)$ & $46(83.6)$ \\
\hline No, n (\%) & $8(26.4)$ \\
\hline \multicolumn{2}{|l|}{ Epidural anesthesia } \\
\hline Yes, n (\%) & $39(70.9)$ \\
\hline T7-T10 level & $-22(40.0)$ \\
\hline Below T10 level & $-17(30.9)$ \\
\hline No, $\mathrm{n}(\%)$ & $16(29.1)$ \\
\hline \multicolumn{2}{|l|}{ Prophylactic PONV medication } \\
\hline Yes, $\mathrm{n}(\%)$ & $37(67.3)$ \\
\hline No, n (\%) & $18(32.7)$ \\
\hline \multicolumn{2}{|c|}{ Intake of $2 \mathrm{CHL}$ drinks $2 \mathrm{~h}$ before surgery } \\
\hline Yes, n (\%) & $37(67.3)$ \\
\hline No, n (\%) & $18(32.7)$ \\
\hline \multicolumn{2}{|l|}{ Suprapubic catheter } \\
\hline Yes, n (\%) & $26(47.3)$ \\
\hline No, n (\%) & $29(52.7)$ \\
\hline \multicolumn{2}{|l|}{ Omission of evening medication } \\
\hline Yes, n (\%) & $22(40.0)$ \\
\hline No, n (\%) & $33(60.0)$ \\
\hline \multicolumn{2}{|l|}{ Omission of pre-medication } \\
\hline Yes, $\mathrm{n}(\%)$ & $17(30.9)$ \\
\hline No, n (\%) & $38(69.1)$ \\
\hline \multicolumn{2}{|c|}{ Intake of $2 \mathrm{CHL}$ drinks on evening after surgery } \\
\hline Yes, n (\%) & $7(12.7)$ \\
\hline No, n (\%) & $48(87.3)$ \\
\hline \multicolumn{2}{|c|}{ Total oral daily intake of fluids after operation, $\mathrm{ml}$} \\
\hline POD 1 (first day after surgery) & 944 \\
\hline POD 2 & 1,313 \\
\hline POD 3 & 1,622 \\
\hline \multicolumn{2}{|c|}{ Total duration of daily mobilization after operation, min } \\
\hline POD 0 (day of surgery) & 29 \\
\hline POD 1 & 110 \\
\hline POD 2 & 178 \\
\hline POD 3 & 339 \\
\hline
\end{tabular}

FT = Fast-track; POD 0 = day of surgery; POD 1 = first day after surgery; POD 2 = second day after surgery; POD 3 = third day after surgery; $\mathrm{CHL}=$ carbohydrate-loaded drink; PONV = postoperative nausea or vomiting.

\section{Outcome Differences of FT vs. TC according to}

Type of Surgery (table 6)

Within the laparoscopic groups, there was no significant difference in primary and total hospital stay $(p=0.13$ and $\mathrm{p}=0.44$, respectively). There also was no difference in overall morbidity $(p=0.49$ ). Major complications and re-operations occurred more frequently in the FT group ( $\mathrm{n}=0$ and $\mathrm{n}=5$ for both major complication rate and reoperation rate in the Lap TC and Lap FT groups, respectively; $\mathrm{p}=0.07$ ).

Within the open groups there was a significant reduction in primary hospital stay in the FT compared to the TC group ( 8 vs. 4.5 days, $\mathrm{p}=0.02$ ). Total hospital stay was shorter as well, although not significantly (8 vs. 5 days, $\mathrm{p}=0.08$ ). There were no significant differences in overall morbidity, re-operation and major and minor complication rates (table 6).

Outcome Differences of Laparoscopic vs. Open Surgery according to Type of Perioperative Care (table 6)

Within the FT groups, both primary and total hospital stay seemed shorter in the laparoscopic group (table 6; reduction 0.5 and 1 day for primary hospital stay and total hospital stay, respectively, $\mathrm{p}=0.08$ and $\mathrm{p}=0.07$, respectively). There were no differences in overall morbidity, and the number of major and minor complications between the open and laparoscopic group $(\mathrm{p}=0.56, \mathrm{p}=$ 0.71 and $p=0.70$, respectively).

Within the TC groups, a reduction of 3 days of both primary and total hospital stay was found in the laparoscopic compared to the open group (table 4; $<<0.01$ and $\mathrm{p}<0.01$, respectively). Overall morbidity rate and re-operation rate were higher in the open group because of a significant higher rate of major complications in this group (table 6; $\mathrm{p}=0.04$ ).

\section{Discussion}

The present study showed that full implementation of a FT care program for patients undergoing an elective segmental colorectal resection is troublesome, since overall 7.4 of the predefined items were achieved. However, despite a relatively low protocol compliance, hospital stay is reduced without affecting overall morbidity and without affecting patient satisfaction. It further indicates that the combination of laparoscopy and FT care might have an amplifying effect.

The implementation of a FT care program for colorectal surgery requires a dedicated and motivated team of 
Table 5. Postoperative results according to care protocol

\begin{tabular}{llcc}
\hline & $\mathrm{TC}(\mathrm{n}=52)$ & $\mathrm{FT}(\mathrm{n}=55)$ & $\mathrm{p}^{\mathrm{a}}$ \\
\hline Overall morbidity <30 days, $\mathrm{n}(\%)$ & $16(30.8)$ & $15(27.3)$ & 0.831 \\
Major complications, $\mathrm{n}(\%)$ & $8(15.4)$ & $8(14.6)$ & 1.000 \\
Anastomotic leakage & 2 & 6 & \\
Abdominal bleeding & 2 & 0 & \\
Abdominal abscess & 2 & 0 & \\
Myocardial ischemia & 2 & 0 & \\
Persistent ileus requiring reoperation & 0 & 1 & \\
Iatrogenic perforation requiring reoperation & 0 & 1 & \\
Minor complications, $\mathrm{n}(\%)$ & $8(15.4)$ & $7(12.7)$ & \\
Urinary tract infection & 1 & 4 & \\
Wound infection & 4 & 1 & \\
Supraventricular arrythmia & 0 & 0 & \\
NSAID gastritis & 1 & 0 & \\
High output stoma with dehydration & 1 & 1 & \\
Persistent ileus treated conservatively & 1 & $7(12.7)$ & 0.516 \\
Reoperation, $\mathrm{n}$ (\%) & $5(9.6)$ & $4.0(2-33)$ & 0.002 \\
PHS, days, median (range) & $6.0(2-36)$ & 6.027 \\
THS, days, median (range) & $6.5(2-36)$ & $4.0(2-33)$ & 0.02790 \\
Readmissions <30 days, $\mathrm{n} \%$ & $3(5.8)$ & $0.9(0)$ & - \\
Mortality <30 days, $\mathrm{n}$ & $0(0)$ & 0.490 \\
\hline
\end{tabular}

FT $=$ Fast-track group; TC $=$ traditional care group PHS = primary hospital stay; THS = total hospital stay. a TC vs. FT.

which the surgeon, anesthesiologist and nursing team are the mainsprings. The 180 degrees reversal in policy affecting current practice of three different disciplines appeared difficult to apply in daily clinical practice. The change of a delayed mobilization into early mobilization, the change of preoperative fasting into preoperative feeding and the introduction of epidural analgesia in laparoscopic surgery were important bottlenecks in the present study. The involved personnel need to be trained, and probably the training must be repeated to maintain a high compliance. The efforts to incorporate such an intensive and multidisciplinary program in a hospital should therefore not be underestimated.

Nonetheless, some of the FT components are already implemented in a modern traditional care program: omission of bowel preparation, restrictive use of abdominal drains and nasogastric tubes, early mobilization and advancement of oral diet, are common practice in many hospitals. Those changes in daily practice are partly instigated by the implementation of laparoscopic surgery.

Despite strenuous efforts of the study coordinators of the involved disciplines to comply with all modalities of the FT protocol, compliance with each of the single modalities was relatively low: only a mean of 7.4 of a potential
13 evaluated FT modalities per patient were achieved. In contrast to what could be expected, protocol compliance did not improve significantly with increasing experience with the program. Only a nonsignificant improvement in protocol compliance with the number of patients receiving epidural analgesia in the second FT period was observed. Possibly, a much longer period of training is necessary to break with the longstanding traditions in traditional care. Still, despite the relatively low compliance, a significant reduction in primary and total hospital stay was observed. This finding seems to suggest that it is rather the protocolized way of perioperative treatment that enhances recovery than the combined effect of each of the single FT modalities. Working according to the fast track protocol, there is no argument about the removal of i.v. drips, epidural catheters, urine catheters, advancement of diet and mobilization. Another important explanation could be the fact that by inviting patients to participate in a 'Fast-track' program, both the patient and the surgeon are committed to work together striving for an enhanced recovery. The clear goals for the patient to reach every day and possibly also the expectations that are being raised by the term 'Fast' may have contributed to the reduced hospital stay as well. 
Table 6. Subanalysis of postoperative results according to care protocol and type of surgery

\begin{tabular}{|c|c|c|c|c|c|c|}
\hline & & $\begin{array}{l}\text { Lap-TC } \\
(\mathrm{n}=17)\end{array}$ & $\begin{array}{l}\text { Lap-FT } \\
(n=29)\end{array}$ & $\begin{array}{l}\text { Open-TC } \\
(\mathrm{n}=35)\end{array}$ & $\begin{array}{l}\text { Open-FT } \\
(n=26)\end{array}$ & $\mathrm{p}^{1}$ \\
\hline \multicolumn{2}{|c|}{ Overall morbidity $<30$ days, $\mathrm{n}(\%)$} & $3(17.6)$ & $9(31.0)$ & $13(37.2)$ & $6(23.1)$ & 0.441 \\
\hline \multicolumn{2}{|c|}{ Major complications, $\mathrm{n}(\%)$} & $0(0.0)$ & $5(17.2)$ & $8(22.9)$ & $3(11.5)$ & 0.167 \\
\hline \multicolumn{2}{|c|}{ Minor complications, $\mathrm{n}(\%)$} & $3(17.6)$ & $4(13.8)$ & $5(14.3)$ & $3(11.5)$ & 0.907 \\
\hline \multicolumn{2}{|c|}{ Re-operation, n (\%) } & $0(0.0)$ & $5(17.2)$ & $5(14.3)$ & $2(7.7)$ & $0.243^{2}$ \\
\hline \multicolumn{2}{|c|}{ PHS, days, median (range) } & $5.0(3-18)$ & $4.0(2-33)$ & $8.0(2-36)$ & $4.5(2-19)$ & $0.000^{3}$ \\
\hline \multicolumn{2}{|c|}{ THS, days, median (range) } & $5.0(3-18)$ & $4.0(2-33)$ & $8.0(2-36)$ & $5.0(2-23)$ & $0.002^{4}$ \\
\hline \multicolumn{2}{|c|}{ Readmissions $<30$ days, n (\%) } & $0(0.0)$ & $3(10.3)$ & $3(8.6)$ & $3(11.5)$ & 0.566 \\
\hline \multicolumn{2}{|c|}{ Mortality <30 days, n (\%) } & $0(0.0)$ & $0(0.0)$ & $0(0.0)$ & $0(0.0)$ & - \\
\hline \multicolumn{7}{|c|}{${ }^{1}$ Lap-TC vs. Lap-FT vs. Open TC vs. Open FT. } \\
\hline & & $\mathrm{p}$ & \multirow{7}{*}{${ }^{4}$ THS } & & & $\mathrm{p}$ \\
\hline \multirow{6}{*}{$\begin{array}{l}{ }^{2} \text { Re-operation } \\
\text { rate }\end{array}$} & Lap TC vs. Lap FT & 0.073 & & Lap TC v & ap FT & 0.437 \\
\hline & Lap FT vs. open TC & 0.557 & & Lap FT v & pen TC & 0.001 \\
\hline & Lap TC vs. open TC & 0.105 & & Lap TC v & pen TC & 0.001 \\
\hline & Lap FT vs. open FT & 0.232 & & Lap FT v & pen FT & 0.069 \\
\hline & Lap TC vs. open FT & 0.247 & & Lap TC v & pen FT & 0.314 \\
\hline & Open TC vs. open FT & 0.428 & & Open TC & open FT & 0.083 \\
\hline \multirow[t]{6}{*}{${ }^{3}$ PHS } & Lap TC vs. Lap FT & 0.131 & & & & \\
\hline & Lap FT vs. open TC & 0.000 & & & & \\
\hline & Lap TC vs. open TC & 0.003 & & & & \\
\hline & Lap FT vs. open FT & 0.077 & & & & \\
\hline & Lap TC vs. open FT & 0.762 & & & & \\
\hline & Open TC vs. open FT & 0.017 & & & & \\
\hline
\end{tabular}

In the present study, overall morbidity between the FT and TC groups was comparable. This is in accordance with data from a meta-analysis comparing FT and traditional care in patients requiring segmental colonic resection [9]. Although the number of readmitted patients seemed higher in the FT compared to the TC group, total hospital stay was shorter in the FT group. A feared complication of FT care programs is an increased incidence of anastomotic leakages, supposed to be caused by the early start of oral feeding. In the present study, more patients with an anastomotic leakage were found in the FT compared to the TC group. This probably represents an unfortunate coincidence, since all leakages occurred in the first FT period and none occurred in the second FT period. In the literature there is no association of anastomotic leakage with the absence of bowel preparation or early feeding [9].

Several randomized trials have demonstrated that a laparoscopic approach reduces hospital stay after segmental colorectal resection for cancer [16-19] and inflammatory bowel disease $[20,21]$ in a traditional care program. Theoretically, the combination of FT care with laparoscopy might be the most optimal combination. In this way, the minimally invasive incisions are combined with the advantages of the optimization package of the FT program. Because the numbers of patients in each subgroup were too small, no robust conclusions can be drawn from the comparison between the four subgroups in which open and laparoscopic surgery as well as TC and FT care were compared. Nonetheless, a reduction in primary and total hospital stay in the open FT compared to the open TC group was found. This might be attributed to the implementation of the FT care program. By combining laparoscopic surgery and FT care, a further decrease in primary and total hospital stay might be achieved. Despite the relatively small number of patients in this pilot study, the findings of the present study justify these findings to be tested in a randomized controlled trial. At present, such a study is being conducted in a multicentered randomized setting [22]. In this RCT the costeffectiveness of the FT program compared to laparoscopy alone or in combination with laparoscopy should be evaluated as well. ASA III patients who were not included in the present study are included in this multicentric trial as 
well. The reason that only ASA I and ASA II patients were included in the present study was because it was the authors' expectation that ASA I and ASA II patients would optimally benefit from the FT protocol. Recent studies, however, have shown that ASA III patients may also benefit from a FT treatment protocol. This was unknown at the time the authors started the study.

In conclusion, successful implementation of a FT program appeared difficult. Despite a relatively low compli- ance, a reduction of 2.5 days of hospital stay was achieved, indicating that it is rather the combination of the protocolized way of perioperative treatment and patient's expectations that enhances recovery. The role and necessity of each single modality as well as the place of laparoscopy both within and compared to such a program remain to be determined.

\section{References}

1 Fearon KC, Ljungqvist O, Von MM, et al: Enhanced recovery after surgery: a consensus review of clinical care for patients undergoing colonic resection. Clin Nutr 2005;24: 466-477.

$\checkmark 2$ Wilmore DW, Kehlet H: Management of patients in fast track surgery. BMJ 2001;322: 473-476.

$\checkmark 3$ Basse L, Thorbol JE, Lossl K, et al : Colonic surgery with accelerated rehabilitation or conventional care. Dis Colon Rectum 2004; 47:271-277.

$\checkmark 4$ Anderson AD, McNaught CE, MacFie J, et al: Randomized clinical trial of multimodal optimization and standard perioperative surgical care. Br J Surg 2003;90:1497-1504.

$\checkmark 5$ Bradshaw BG, Liu SS, Thirlby RC: Standardized perioperative care protocols and reduced length of stay after colon surgery. J Am Coll Surg 1998;186:501-506.

6 Delaney CP, Fazio VW, Senagore AJ, et al: 'Fast track' postoperative management protocol for patients with high co-morbidity undergoing complex abdominal and pelvic colorectal surgery. Br J Surg 2001;88:15331538.

7 Gatt M, Anderson AD, Reddy BS, et al: Randomized clinical trial of multimodal optimization of surgical care in patients undergoing major colonic resection. Br J Surg 2005; 92:1354-1362. $\checkmark 8$ Raue W, Haase O, Junghans T, et al: 'Fasttrack' multimodal rehabilitation program improves outcome after laparoscopic sigmoidectomy: a controlled prospective evaluation. Surg Endosc 2004;18:1463-1468.

$\checkmark 9$ Wind J, Polle SW, Fung Kon Jin PH, et al: Systematic review of enhanced recovery programmes in colonic surgery. Br J Surg 2006; 93:800-809.

10 Bardram L, Funch-Jensen P, Kehlet H: Rapid rehabilitation in elderly patients after laparoscopic colonic resection. Br J Surg 2000;87: 1540-1545.

11 Basse L, Hjort JD, Billesbolle P, et al: A clinical pathway to accelerate recovery after colonic resection. Ann Surg 2000;232:51-57.

12 Kehlet H, Mogensen T: Hospital stay of 2 days after open sigmoidectomy with a multimodal rehabilitation programme. Br J Surg 1999;86:227-230.

13 Zutshi M, Delaney CP, Senagore AJ, et al: Shorter hospital stay associated with fastrack postoperative care pathways and laparoscopic intestinal resection are not associated with increased physical activity. Colorectal Dis 2004;6:477-480.

14 Basse L, Jakobsen DH, Bardram L, et al : Functional recovery after open versus laparoscopic colonic resection: a randomized, blinded study. Ann Surg 2005;241:416-423.

15 King PM, Blazeby JM, Ewings P, et al: Randomized clinical trial comparing laparoscopic and open surgery for colorectal cancer within an enhanced recovery programme. Br J Surg 2006;93:300-308.
16 Abraham NS, Young JM, Solomon MJ: Metaanalysis of short-term outcomes after laparoscopic resection for colorectal cancer. Br J Surg 2004;91:1111-1124.

17 Curet MJ, Putrakul K, Pitcher DE, et al : Laparoscopically assisted colon resection for colon carcinoma: perioperative results and long-term outcome. Surg Endosc 2000;14: 1062-1066.

18 Lacy AM, Garcia-Valdecasas JC, Delgado S, et al: Laparoscopy-assisted colectomy versus open colectomy for treatment of non-metastatic colon cancer: a randomised trial. Lancet 2002;359:2224-2229.

19 Schwenk W, Bohm B, Muller JM: Postoperative pain and fatigue after laparoscopic or conventional colorectal resections: a prospective randomized trial. Surg Endosc 1998;12:1131-1136.

20 Maartense S, Dunker MS, Slors JF, et al : Laparoscopic-assisted versus open ileocolic resection for Crohn's disease: a randomized trial. Ann Surg 2006;243:143-149.

21 Milsom JW, Hammerhofer KA, Bohm B, et al: Prospective, randomized trial comparing laparoscopic vs. conventional surgery for refractory ileocolic Crohn's disease. Dis Colon Rectum 2001;44:1-8.

22 LAFA Study: 2006. Ref Type: Generic. 